\title{
ORIGEN Y DIFUSIÓN DE LA ICONOGRAFÍA DEL ÁGUILA BICÉFALA EN LA PLATERÍA RELIGIOSA ESPAÑOLA E HISPANOAMERICANA
}

\author{
POR \\ MARÍA DEL CARMEN HEREDIA MORENO \\ Universidad de Alcala de Henares
}

\begin{abstract}
We study the graphics surces of the spanish monstrances whit knot composed of two-headad eagle. We also stablish the origin of its iconography in an engraving printed by María Eugenia Baer about the middle of the 17 th century. Finally, we also try to study the spreading of the two-headad eagle in spanish and spanish-american silversmithing.
\end{abstract}

En el año 1980 dimos a conocer la espléndida custodia de sol de la parroquia de Valtierra, obra barroca labrada en Madrid por Cristóbal de Alfaro, maestro platero natural de aquella localidad navarra ${ }^{1}$. La riqueza y calidad de la pieza, el peculiar diseño de su basamento y sol, así como la original iconografía de su astil con águila bicéfala coronada se alejaban por completo de los modelos navarros contemporáneos y de los ejemplares cortesanos conocidos hasta el momento, si bien los datos documentales y la marca de Juan Muñoz apuntaban a la escuela madrileña y a unas fechas precisas en torno a 1700.

En los últimos años, la reciente publicación de tres obras parecidas descubiertas en Orduña (Alava), Alba de Tormes (Salamanca) y Cartes (Cantabria) ${ }^{2}$, más la licalización por nuestra parte de fotografías de otras dos custodias similares pertenecientes a la parroquia de Alquézar en Barbastro (Huesca) y al cabildo catedral de Madrid, que se exhibieron en las exposiciones Iberoamericana de Sevilla de 1929 y en la de Orfebrería y Ropas de Culto del Museo Arqueológico Nacional en el año $1941^{3}$, suman un total de seis ejemplares que se ajustan sustancialmente al

1 M. C. Garcta Gainza; M. C. Heredia Moreno; J. Rivas Carmona y M. Orbe Sivatte: Catáloqo Monumental de Navarra I. Merindad de Tudela, Pamplona, 1980, pág. 412, lám. 685.

2 M. Portilla: Catálogo Monumental. Diócesis de Vitoria. Vitoria 1988, págs. 699-700, fotos 468 y 470 ; M. PÉREZ Hernández: Orfebrería religiosa en la Diócesis de Salamanca, Salamanca, 1990, pág. 189, fig. 132 y S. CARRETERo Rebes: Platería religiosa del Barroco en Cantabria, Santander, 1987, pág. 105, núm. 66, lám. 32.

3 Catáloqo de la Exposición de Orfebrería y Ropas de Culto. Museo Arqueolóqico Nacional, Madrid, 1941 (Sección de Orfebrería por E. Cams Cazorla), Sala VII, núms. 1-2 y Exposición Iberoamericana. Catáloqo de la Sección de Arte Antiguo. Palacio Mudéjar, Sevilla, 1930, Sala I, núm. 185. 
mismo modelo y que fueron labradas a lo largo del último tercio del siglo xvir y hasta 1715 aproximadamente. Todas ellas son custodias de sol de estilo barroco, con el nudo en forma de gran águila bicéfala coronada con las extendidas y con adornos de pedrería.

A este grupo habría que añadir además la custodia de plata dorada, perlas, piedras preciosas y esmaltes translúcidos que don Juan Domingo de Haro y doña Inés de Zúñiga, VII condes de Monterrey a raíz de su matrimonio en el año 1656, donaron al convento de Agustinas de Salamanca. Presenta también un gran águila bicéfala en lugar destacado del astil, si bien su basamento y sol tienen un diseño distinto al de las anteriores obras e incorpora pinturas con los retratos de los donantes en el pedestal, la imagen de la Inmaculada en el centro del águila y la inscripción "Monterrey» en el sol ${ }^{4}$. La custodia se ha clasificado como española de la segunda mitad del siglo xvir y como salmantina de fines de esta centuria (Fig. 1).

Si exceptuamos esta última pieza de los condes de Monterrey, la más sobria y de cronología más temprana es la custodia de San Martín de Cartes (Cantabria) $(64 \mathrm{cms}$ de alto), que todavía conserva el pie de planta cruciforme con ensanches curvos en los frentes y cuerpo interior convexo, astil liso y sol con rayos rectos y flameados, reduciendo su adorno a pedrería sobrepuesta en el cerco del viril. Lleva en la pestaña del pie la inscripción "RAIFELPE 1680" y se ha atribuido con reservas a la escuela madrileña. Tres años después esta fachada la custodia de Santa María de Orduña $(87 \mathrm{~cm})$ (Fig. 2), de traza semejante a la anterior pero de aspecto más rico por la adición de pedrería sobre la corona, plumas del águila y centro de las estrellas. Su pestaña contiene la inscripción "ESTA CVSTODIA ES DE LA YGLESIA DE SANTA MARIA DE LA CIVDAD DE HORDVÑA. MANDOLA HACER A SV COSTA I LA DIO DE LIMOSNA EL CAPITAN DON ANTONIO DE ODIAGA LEZAMA. AÑO DE 1683. EGECVTOLA RAFAEL GONÇALES SOBERA, PLATERO DEL REI». La custodia de Alquézar (Huesca) (Fig. 3), de pie circular con sobrepuestos fundidos, gollete cilíndrico, astil con un cuerpo esferoide y otro en cuarto de bocel con asas, y sol de rayos rectos y flameados, se fechó en la Exposición del año 1941 entre 1710 y 1715, aunque quizás se labrase unos años antes.

Respecto de las custodias de los Carmelitas de Alba de Tormes $(79,7 \mathrm{~cm})$ y del Cabildo Catedral de Madrid, hoy desaparecida (Fig. 4), ambas son tan semejantes entre sí y a la de Valtierra que parecen obras del mismo artífice. Todas ellas tienen pie mixtilíneo, espectacular sol de crestería con estrellas y niños desnudos fundidos sobre el basamento, astil o corona. La salmantina lleva la inscripción "SEÑOR INES SIEMPRE A TUS PIES» y se ha relacionado también con la escuela madrileña del último cuarto del siglo xvII aunque sin apoyo documental alguno. Sin embargo la de Valtierra sí está documentada como tal obra madrileña igual que la custodia de Orduña, lo que nos permite hacer a partir de ellas ciertas consideraciones que ayuden a definir el origen y evolución de su diseño e iconografía a lo largo de casi medio siglo. La de Valtierra es un magnífico ejemplar $(70,5 \mathrm{~cm})$ de plata sobredorada, oro y piedras preciosas (Fig. 5), elevado sobre pie oval mixtilíneo con pestaña moldurada y gran cuerpo convexo con repujado de roleos vegetales y sobrepuestos fundidos de querubines. El gollete cilíndrico y los dos cuartos de bocel superpuestos se conectan a la base mediante carnosos tornapuntas vegetales que incorporan sendos desnudos infantiles fundidos sedentes. A continuación se alza el gran nudo en forma de águila bicéfala, también fundida, con adorno de pedrería y con corona imperial donde se sientan otros dos desnudos infantiles portando cuernos de la abundancia. El sol, con cerco polilobulado y adornos de piedras preciosas, contiene un aparatoso resplandor de crestería calada vegetal,

4 La reproduce M. Gómez Moreno: Catálogo Monumental de la Provincia de Salamanca, Valencia, 1967 y la comenta y hace un amplio estudio de los Condes de Monterrey y su conexión con el convento de Agustinas de Salamanca A. MA DRUGA REAL: Arquitectura barroca salmantina. Las agustinas de Monterrey, Salamanca, 1983, págs. 135-136 y 31-48. También la mencionan Casaseca Casaseca: "La orfebrería en Salamanca", en Varios: Salamanca. Geoqrafía. Historia. Arte. Cultura, Salamanca, 1986, pág. 508, y M. Pérez Hernández: op. cit., pág. 189, núm. 131. 

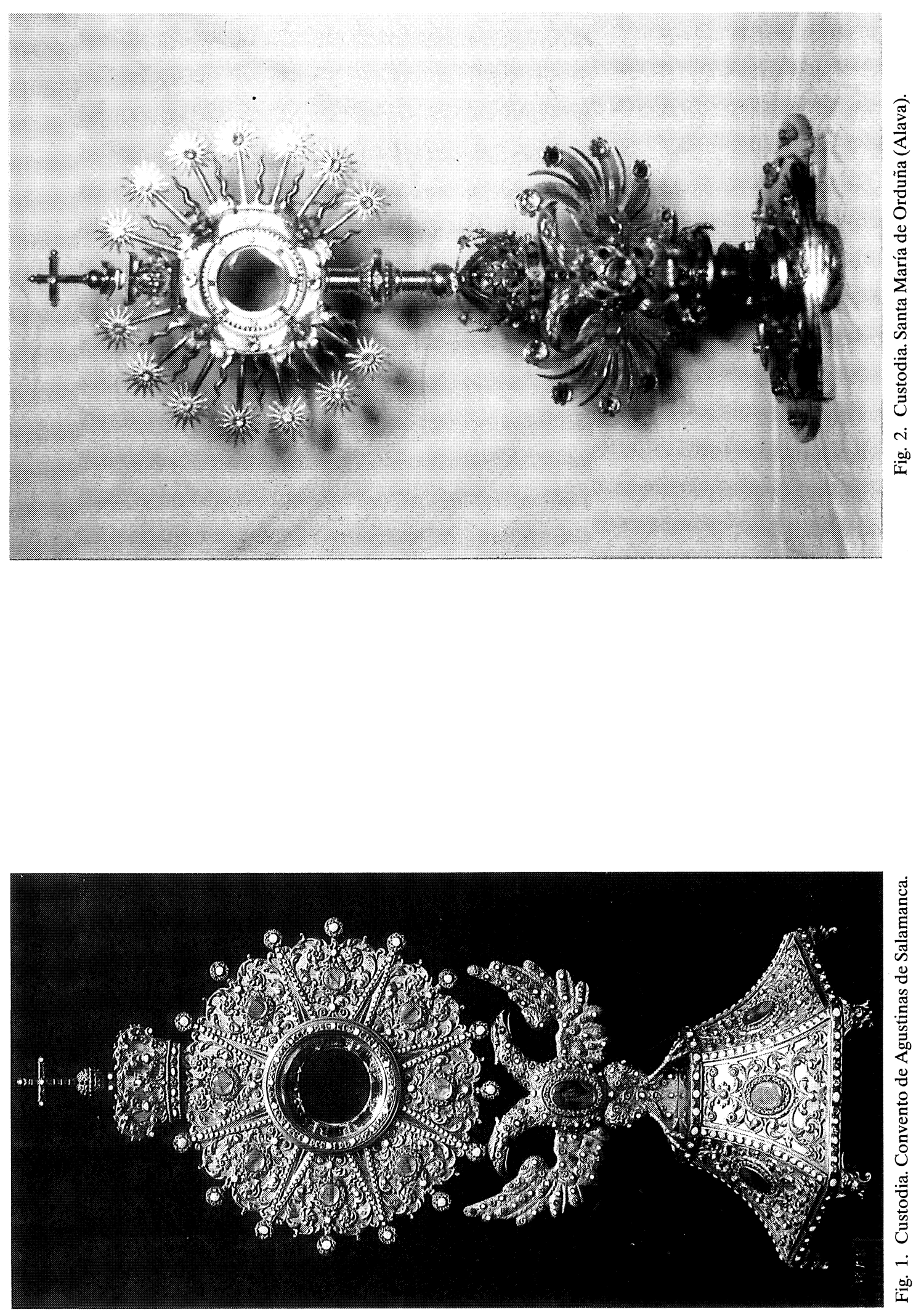

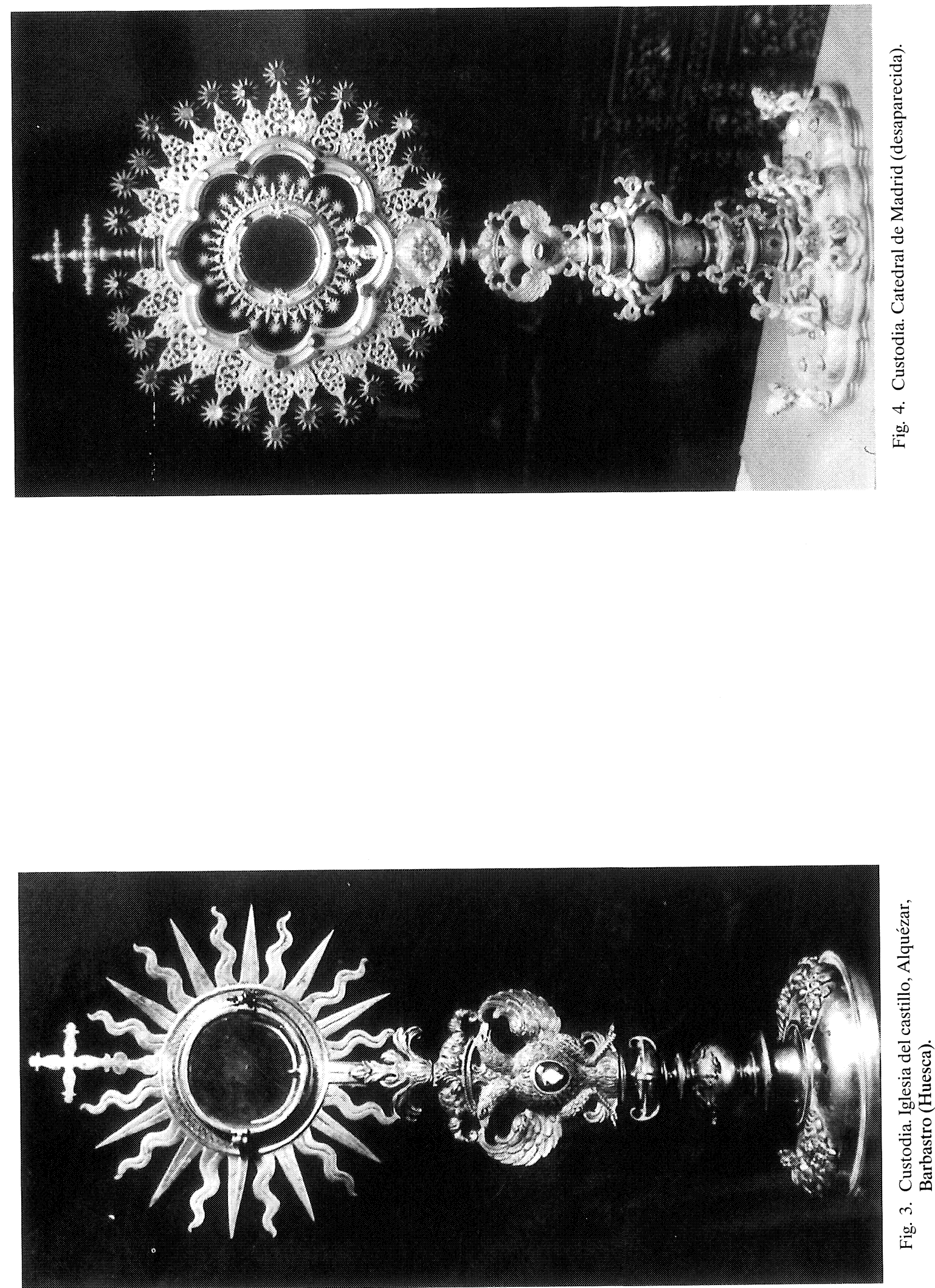
culminada en estrellas de rayos rectos y flameados alternantes. El viril interior es de oro con pedrería en el cerco y resplandor de carnosos rayos.

La custodia lleva impresa la señal del marcador madrileño JV/MUÑOZ junto con la burilada y consta por la documentación que fue la pieza de examen labrada por don Cristóbal de Alfaro, natural de Valtierra, en torno a 1700 para acceder al grado de maestro ${ }^{5}$. No obstante, como existen otras noticias sobre varios artífices de este mismo apellido e, incluso, del mismo nombre, es preciso hacer algunas aclaraciones al respecto.

Por una parte, entre los años 1678 y 1729 residieron en la Corte dos miembros plateros de esta familia. El padre, Cristóbal de Alfaro, desempeñó el puesto de platero de cámara por su Majestad en el ramo de oro a partir de 1678, mientras que su hijo mayor, Benito de Alfaro, fue ayuda de la furriera desde $1712{ }^{6}$. Por otra parte, se conoce también que un platero de nombre Cristóbal de Alfaro fue bautizado en la localidad navarra de Valtierra el 25 de noviembre de $1654 \mathrm{y}$ que otro artífice, llamado Cristóbal Miguel Antonio de Alfaro recibió el Bautismo en la misma parroquia el once de febrero de 1723. Según la bibliografía local, estos dos últimos también trabajaron en Madrid en donde labraron varias obras para la parroquia de su pueblo natal, Valtierra. Cristóbal cuatro coronas para las Vírgenes del Rosario y de la Esperanza, y de sus respectivos Niños, en 1693; y Cristóbal Miguel Antonio la custodia en el año 1775. En esta última el platero utilizó como materiales quinientos ducados navarros de plata y no cobró por su trabajo que ascendió a dieciocho libras navarras de peso ${ }^{7}$. Por tanto, nos hallamos ante una familia de plateros, de los cuales es bastante probable que el Cristóbal de Alfaro bautizado en Valtierra en el 1654 pueda identificarse con el maestro madrileño, padre de Benito, que alcanza el puesto de platero de cámara en 1690. Sin embargo, no es posible que la custodia de Valtierra fuese labrada por este artífice, ya que la ocupación de este cargo indica que su examen de maestro hubo de realizarse necesariamente con anterioridad a esta fecha, pero, como antes dijimos, la marca que ostenta la custodia -JU/MUÑOZ - es la que el marcador de villa Juan Muñoz utilizó entre 1695 y 1711, sustituida a partir de entonces por otra variante compuesta por la cronológica más su apellido completo ${ }^{8}$. Tampoco es posible que la custodia de Valtierra fuese labrada en 1775 por Cristóbal Miguel Antonio, ya que, estilísticamente, por la documentación y por la marca, se trata de una obra barroca de hacia 1700. Por todo ello hemos de deducir que existió un segundo artífice llamado Cristóbal de Alfaro - posiblemente hijo del platero de cámara, hermano menor de Benito y, quizás, padre o tío de Cristóbal Miguel Antonio- que se examinó en Madrid entre 1695 y 1712 y al que le tocó en suerte realizar la custodia que nos ocupa. Su viril de oro y sus engarces de piedras preciosas permiten suponer, además, que alcanzó la maestría en las especialidades de oro y de plata simultáneamente. De esta forma, el número de platero de apellidos Alfaro que trabajan en Madrid se eleva a cuatro: Cristóbal, su hijo Benito, Cristóbal el Mozo -posible hijo del primero y hermano del segundo- y Cristóbal Miguel Antonio, probable hijo de uno de los dos hermanos. El origen navarro de la familia debió motivar el envío de la custodia a Valtierra.

Al mismo tiempo, la documentación de la custodia de Valtierra nos ha permitido, de manera excepcional, conocer una pieza de examen madrileña de hacia 1700 y deducir también algunos datos de interés. Recordemos que en algunas ciudades como Barcelona las pruebas de maestría se iniciaron en el siglo $\mathrm{xv}^{9}$, pero se fueron generalizando, haciéndose obligatorias y regulándose

5 M. C. Garcia Gainza y otros: Catáloqo.......Tudela, pág. 412. Dato procedente del archivo parroquial de Valtierra.

${ }^{6}$ F. MARTín: Catálogo de la plata del Patrimonio Nacional, Madrid, 1987, págs. 14 y 393.

7 F. Zapatero Pérez: Monografía de la villa de Valtierra, Pamplona, 1935, pág. 122, según datos recogidos de T. BiURRUN SotiL: «Para el inventario de la riqueza artística de la Diócesis de Pamplona», Boletín Oficial Eclesiástico, 1929.

8 F. MARTin: op. cit., pág. 383 y A. Fernandez, R. MunOa y J. Rabasco: Enciclopedia de la plata española y virreinal americana, Madrid, 1985, num. 580.

9 N. Dalmases; D. Giralt Miracle y R. Manent: Plateros y joyeros de Cataluña, Barcelona, 1985, pág. 20. 
su funcionamiento a lo largo del siglo XVI y comienzos del XVII -Sevilla en $1527^{10}$, Pamplona desde $1554^{11}$, Zaragoza a partir de $1617^{12}$, etc.-. Además se conservan los libros de Exámenes de los plateros en Valencia ${ }^{13}$, Barcelona ${ }^{14}$ a partir del año 1500 y Pamplona entre 1691 y $1832{ }^{15}$, así como cuatro Libros de Dibujos para exámenes de la platería sevillana fechados dos de ellos en 1699 y los otros dos en $1754{ }^{16}$.

Respecto de la orfebrería madrileña ${ }^{17}$, ni las Reglas de la Cofradía dle año 1575, ni sus primeras Ordenanzas de 1600, que tratan sobre aprendices, contemplan este tema de las aprobaciones, las cuales aparecen mencionadas por primera vez en el proyecto de estatutos de 1604. A partir de entonces y a lo largo de todo el siglo XVII las Ordenanzas de 1624, 1627 y 1695 desarrollan el tema de los exámenes insistiendo en la importancia del dibujo y regulando qué tipo de piezas habían de realizar los aspirantes según su especialidad, de oro o de plata.

Por lo tanto, desde el año 1624 y a lo largo de todo el siglo xVII los plateros madrileños se examinaron mediante el dibujo y ejecución de una obra propuesta por el tribunal, pero no parece que durante todo ese tiempo existiese ningún Libro de Dibujo hasta que las Ordenanzas de 1771 lo citan de forma expresa ${ }^{18}$. Es decir, no poseemos ninguna información directa sobre qué modelos concretos se utilizaban en los exámenes madrileños de la segunda mitad del siglo xvil. Pero es bastante probable que desde finales del siglo xvi los plateros poseyesen dibujos y grabados de platería en láminas sueltas, los cuales servirían de ejemplo a los aprendices durante su etapa de formación y de repertorios a los examinadores a la hora de determinar la prueba a realizar por dichos aprendices en el momento de acceder a la maestría, como sucedía en otros gremios artísticos ${ }^{19}$. Algunos de estos dibujos pudieron conservarse y utilizarse durante largo tiempo igual que sucedió, por ejemplo, en el gremio sevillano de carpinteros de lo blanco ${ }^{20}$.

En cualquier caso, la custodia de Valtierra, labrada por Cristóbal de Alfaro en torno a 1700, es la única pieza de examen madrileña de época barroca que nos ha llegado. Esta circunstancia la convierte en un ejemplo excepcional, con independencia de su gran calidad y de su particular iconografía. El tribunal debió ordenar a Cristóbal de Alfaro que realizase una custodia con unas características determinadas, para lo cual le mostraría posiblemente un modelo concreto, dibujo o grabado, de una de estas láminas sueltas existentes en poder de la corporación. La cercanía de la Corte podría explicar la presencia del águila bicéfala coronada, y el entorno familiar del platero, hijo de un platero de cámara, nos aclararía también la destreza de Cristóbal de Alfaro el Mozo, familiarizado desde su infancia con estos temas.

10 M. J. Sanz SerRano: El gremio de plateros sevillano. 1344-1868, Sevi1la, 1991, págs. 35 y 37 y documentos núms. 4 y 5.

11 M. Orbe Sivatte y A. Orbe Sivatte: "Aproximación al funcionamiento de los plateros de Pamplona». Príncipe de Viana, núm. 192 (1991) 117.

12 J. F. EstebAN LoRENTE: La platería de Zaragoza en los siglos XVII y XVIII, Madrid, 1981, vol. I, pág. 21.

13 A. Igual Ubeda: El gremio de plateros. Ensayo de una historia de la platería valenciana, Valencia, 1956, y D. GARcia CANTUS: El gremio de plateros de Valencia en los siglos XVIII y XIX, Valencia, 1985.

14 N. Dalmases: "La orfebrería barcelonesa del siglo xvir a través de los "Libres de Passantíesm", Revista del Departamento de Historia del Arte, núms. 3-4, págs. 5- 30.

15 M. Núnez de Cepeda: Los antiguos gremios y cofradias de Pamplona, Pamplona 1948, pág. 229. M. C. Garcia GainZA: Dibujos Antiguos de los Plateros de Pamplona, Pamplona, 1991.

16 M. J. Sanz Serrano: Antiguos Dibujos de la Plateria Sevillana, Sevilla, 1986.

17 Dado que los textos de las ordenanzas no se han publicado, hemos de guiarnos por los comentarios que sobre ellas hace J. M. CRUz VAldovinos: Los plateros madrileños. Estudio histórico jurídico de su organización corporativa, Madrid, 1983.

18 Incluso después de 1771 sólo tenemos noticia de los Libros de Dibujos de los años 1781,1782 y 1793 y unos pocos exámenes con sus respectivos dibujos fechados entre 1797 y 1817. J. M. Cruz Valdovinos: «Exposición de Dibujos. Gremio de Joyeros y Plateros de Madrid», Iberioya, 1985, págs. 24, 16 y 13, y 12 a 32.

19 J. J. Martín GonZález: El artista en la sociedad española del siglo XVII, Madrid, 1984, págs. 215 y ss.

20 M. A. Toajas Roger: Diego López de Arenas. Carpintero, alarife y tratadista en la Sevilla del siglo xvil, Sevilla, 1989, págs. 203 y ss. 
Pero estas razones no son suficientes dado que el símbolo imperial ya no era distintivo oficial de los Austrias españoles y se había eliminado del escudo del rey desde los tiempos de Felipe II. Hay que hacer un breve repaso del origen y desarrollo de este motivo iconográfico en las artes plásticas de la Península Ibérica para intentar determinar las causas de su pervivencia en el siglo xvir y de su incorporación a la platería religiosa en la segunda mitad de esta centuria.

Desde la perspectiva que ahora nos interesa, el punto de partida de la iconografía del águila bicéfala se remonta al año 1508 y a la ciudad de Trento, a raíz de la adopción del título del imperio romano por parte de Maximiliano I con la consiguiente incorporación de este símbolo a su propio escudo ${ }^{21}$. Once años después, el tema se introduce en la Península en un grabado de Carlos V como rey de España aspirante al imperio, que lleva la fecha de $1519^{22}$. A partir de aquí -además de las columnas con el lema "Plus Ultra", creado en 1516, y de la esfera terrestre- el escudo imperial incorpora el águila bicéfala de los Ausburgo y la corona imperial rematada en cruz, distintiva del Sacro Imperio Romano y adoptada también por los Ausburgo como sus sucesores legítimos, tanto en el poder temporal como en el espíritul, con el compromiso de defender y expandir la Fe Católica por todo el orbe conocido. Parece ser que fue la corona del Sacro Imperio que hoy se guarda en el Museo de Viena, hasta el siglo xix creída de Carlomagno y ahora considerada de la época de Enrique II y Conrado II, la que ciño las sienes de Carlos V en el año 1520 en la ceremonia de su coronación ${ }^{23}$. En España el escudo imperial con el águila bicéfala coronada se difunde en lugar preferente en todas las obras relacionadas de alguna manera con el emperador, tanto en la decoración arquitectónica como en rejerías, grabados, joyas, etc. ${ }^{24}$.

Sin embargo, esta iconografía imperial no se introdujo en la platería religiosa del siglo xvI, al menos no conocemos ningún ejemplo anterior a la segunda mitad del siglo xvil y primeros años del XVIII donde se inscriben todas las custodias que estamos tratando, coincidiendo, cronológicamente, con los últimos años del reinado de Felipe IV y, sobre todo, con el de Carlos II (16651700), y con el comienzo del reinado de Felipe V hasta el Tratado de Utrech (1713). En estos momentos el escudo real ya hacía más de un siglo que había eliminado el águila bicéfala, desde la incorporación de Felipe II al trono en 1556, por lo que su presencia en obras de platería religiosa de la época de los últimos Austrias y de Felipe V debe obedecer a motivos muy concretos, como ahora veremos.

En el año 1640 Francisco Martínez publicó en Madrid el Sumo Sacramento de la Fe obra del jesuita Francisco Aguado, precedido por una hermosa portada barroca grabada por María Euge-

21 Se conservan varios ejemplares en torno a esta fecha, como el escudo en óleo sobre tabla de Brujas o la xilografía de Hans Burgkmair, vid. Catálogo de la Exposición Reyes y Mecenas, Madrid, 1992, núms. 203 y 179.

22 E. PÁez Rios: Los Austrias. Grabados de la Biblioteca Nacional, Madrid, 1993, núm. 31.

23 Sobre el contenido y el origen del escudo de Carlos V pueden consultarse los trabajos de E. RosENTHAL: «Die "Reichskrone", die "Wiener Krone" und die "Krone Karls des Grossen" um 1520", Jarhbuch der Kunsthistorischen Sammlungen in Vien, 1971, págs. 7-48; "The invention of the columnar device of emperor Charles V at the court of Burgundy in Flandes in 1516", Journal of the Warburg Institut, 1972, y "Plus Ultra, Non Plus Ultra and the columnar device of Emperor Charles V", Journal of the Warburg Institut, 1971 y The palace of Charles Vin Granada, Londres, 1985. Agradezco a la Dra. I. Mateo sụ orientación bibliográfica sobre este punto.

Sobre la corona y demás "regalia" de los emperadores del Sacro Imperio pueden consultarse M. LEITHE-JASPER y R. Distelberger: The Kunsthinstorische Museum Vienna. The treasury and the collection of sculpture and a decorative arts, London, 1982, págs. 8-11; D. Gaborit-Chopin: Regalia. Les instruments du sacre des rois de France. Les "Honneurs de Charlemagne», París, 1987, sobre todo págs. 85 y ss. y M. Schulze-Dorrlam: "La corona del Sacro Imperio", Investigación y Ciencia, Madrid, 1993, págs. 8-17.

$24 \mathrm{El}$ escudo imperial con águila bicéfala, bajo diversas variantes, aparece en lugar destacado en el palacio de Carlos $\mathrm{V}$, fuente y puerta de la Alhambra de Granada, alcázar de Toledo, Colegio de San Ildefonso de la universidad de Alcalá de Henares, palacio de El Pardo, monasterio de Yuste, reja del presbiterio de la catedral de Toledo, etc., etc., en la joyería cortesana del siglo XVı aparece también el águila bicéfala de los Ausburgo (Vid. M. J. SAnz Serrano: «Joyería nobiliaria y popular en los retratos de corte del siglo xvI", actas del congreso Madrid en el contexto de lo hispánico desde la época de los Descubrimientos, Madrid, 1994, T. I, págs. 719-734. 



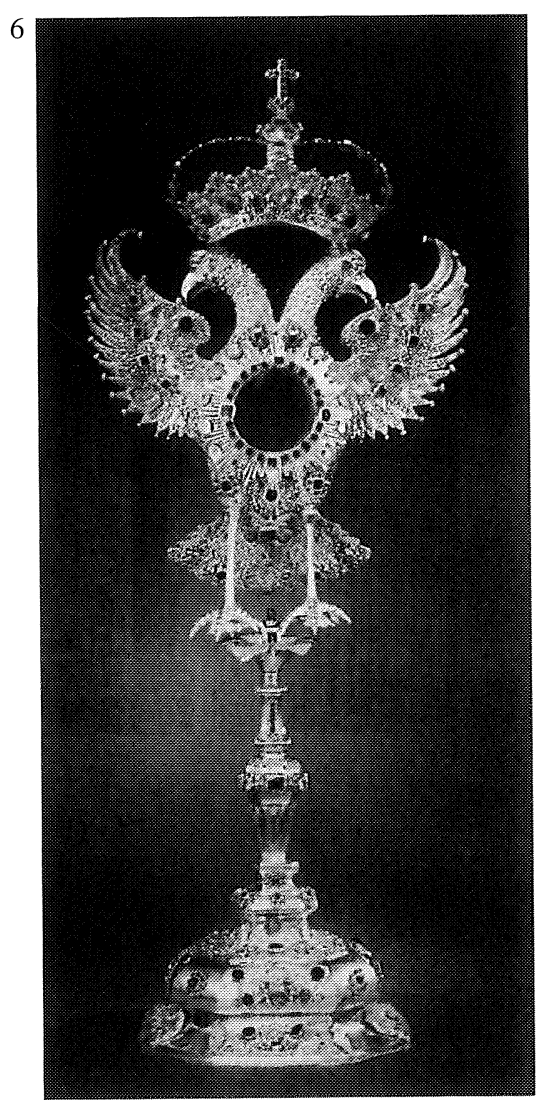

Fig. 5. Custodia. Santa María de Valtierra (Navarra). Fig. 6. Custodia. Arzobispado de Popayán (Colombia). Fig. 7. Portada del «Sumo Sacramento de la Fe». 
nia Beer ${ }^{25}$, cuya compleja iconografía tiene mucha relación con el tema que nos ocupa (Fig. 7). El grabado muestra, sobre un elevado pedestal y entre las personificaciones de la Piedad y la Fortale$\mathrm{za}^{26}$, el escudo imperial sujeto por gran águila bicéfala coronada, donde apoya una esfera terrestre que soporta una custodia con la Forma en medio de un gran sol inmerso en una gloria de nubes y querubines ${ }^{27}$. Completan y aclaran el significado del conjunto una serie de inscripciones. En el frente del pedestal el título, dedicatoria y autoría, seguido del lugar de edición, impresor y fecha: SVMO SACRAMENTO DE LA FE Teforo del nombre christiano A la S(acra), C(atólica), R(eal) Mag(esta)d del Rey N(uestro) S(eñor) D(on) Philipe IIII el Grande. Por el P(adre) Francisco Aguado de la Com(añia) de Iefus. Predicador de fu Mag(esta)d Natural de M(adri)d Con privilegio. En Madrid por Fran(cis)co Martínez Año 1640. Bajo el escudo, «Maieftate extollit» (es decir, "con majestad eleva»). Al pie de la custodia, en la filacteria que ondea sobre el globo terráqueo, «SCABELLVUM PEDVUM TVORVM" ("Escabel de tus pies»). En el zócalo de la Piedad, «Pietate collit» ("Honra con su piedad») y en su filacteria "MANE NOBISCVM DOMINE» ("Señor, quédate con nosotros»). Finalmente, bajo la figura de la Fortaleza, «Poteftate defendit» ("Defiende con su poder") y en su filacteria "APREHENDO ARMA ET SCVTVM" ("Cojo las armas y el escudo").

El libro está dedicado a Felipe IV, monarca que se distinguió a lo largo de toda su vida por su piedad al Santísimo Sacramento. Así lo reconocen diversos escritos contemporáneos que, al comentar la procesión del Corpus madrileño, resaltan este carácter del soberano con expresivas frases: «el mayor venerador del Sacramento y el más asistente a su culto» (Pedro Becerra) o "venía su Majestad Católica (ponga Dios a sus pies a los enemigos de la Iglesia) dando ejemplo de la Fe y devoción al Santísimo Sacramento, tan propio de la Casa de Austria..." (Valenzuela) ${ }^{28}$. Su fervor a la Eucaristía lo impulsó a erigir en el año 1640, el mismo de la edición del libro, un suntuoso relicario en la sacristía de la capilla real del viejo alcázar de Madrid, recubierto de jaspes, mármoles, bronces y materiales preciosos, coincidiendo con un momento crítico de la política española por la entrada de Francia en la guerra de los treinta años y por la sublevación de Cataluña ${ }^{29}$. Aguado recoge todas estas circunstancias en su dedicatoria que comienza: «Hállome obligado por no pocos títulos a ofrecer a v. Magestad este pobre y humilde trabajo...», insistiendo en la profunda devoción de la Casa de Austria y, sobre todo, de Felipe IV, al Santísimo Sacramento, único aliado capaz de vencer a los enemigos de España en estos momentos difíciles y a cuyo fervor debía el monarca su poder. Todo ello permite suponer que, a través del grabado de la portada, se pone de manifiesto que el rey católico, continuando la línea de los Ausburgo, herederos del Sacro Imperio, es el soporte terreno de la Eucaristía, en cuya defensa y exaltación empeña todos los recursos a su alcance ${ }^{30}$. Por lo tanto, la reproducción del motivo imperial de

\footnotetext{
25 Noticias sobre esta grabadora hija del flamenco Cornelio de Beer en A. GALLEGo: Historia del grabado en España. Madrid, 1979, págs. 169-170.

${ }^{26}$ La Fortaleza lleva coraza, casco, lanza, escudo y rama de roble, de acuerdo con la iconología de Ripa, mientras que la Piedad porta cruz y templo en las manos derecha e izquierda, respectivamente, atributos que se corresponden mejor con la imagen de la Fe cristiana de Ripa aunque sin reproducirla literalmente. Vid. C. RIPA: Iconología, Madrid, 1987. vol. I, págs. 437 y ss. y vol. II, págs. 401-402. En este sentido hay que tener en cuenta que, según Allo Manero que hace el prólogo de esta edición, el propio Pacheco recomendaba añadir, quitar y modificar las alegorías de Ripa.

27 Este grabado esta reproducido por J. Carrete Parrondo; F. Checa Cremades, y V. Bozal: El grabado en España, Madrid, 1987, pág. 254, Fig. 317. Agradezco al Dr. A. Martínez Ripoll su ayuda desinteresada sobre este punto.

28 J. Portus Pérez: La antigua procesión del Corpus Christi en Madrid, Madrid, 1993, págs. 98-99.

${ }_{29}$ El relicario lo construyó Alonso Carbonel y en la decoración intervinieron Bartolomé Zumbigo y Juan Bautista Sormano para los mármoles, Joachim Pallares para los bronces, Juan Sutil Cornejo hizo los relicarios y de las Pinturas se encargaron Jusepe Leonardo y Félix Castello (Vid. V. Gerard: «Los sitios de devoción en el alcázar de Madrid: Capilla y oratorios" Archivo Españo1 de Arte, 1983, núm. 56, págs. 280-281.

30 Esta idea del poderío militar en defensa de la Fe fue también tradicionalmente utilizada por los Austrias españoles como parte de la decoración del «Salón de la Virtud del príncipe» (Vid. J. Brown: Un palacio para el rey, Madrid, 1985. págs. 155-162).
} 
Carlos V se utiliza aquí fundamentalmente al servicio de una idea religiosa, aunque también de propaganda política: Felipe IV el Grande es el Emperador Cristiano -Sacra, Católica, Real Majestad- que, continuando la tradición de Carlomagno y sus sucesores, defiende y difunde el dogma de la Eucaristía por todo el orbe, apoyado en su poder terreno y en su piedad ${ }^{31}$. La devoción de Felipe IV al Santísimo es también la idea principal de los jeroglíficos de las honras funerarias del monarca celebradas en el convento de la Encarnación de Madrid en 1666 y de la oración fúnebre pronunciada por el Padre Maestro Fray Miguel de Cárdenas de la Orden de Nuestra Señora del Carmen de la Antigua Observancia, donde de nuevo se hace referencia al suntuoso relicario construido por el soberano en la capilla real del alcázar madrileño ${ }^{32}$.

En este ambiente no es extraño que los plateros cortesanos se hagan eco también del fervor del monarca y lo reinterpreten en el grupo de custodias que estamos tratando, máxime cuando tenían tan próximo un modelo a seguir en el grabado de María Antonia Beer de 1640.

Es evidente que los VII Condes de Monterrey, muy relacionados desde su infancia con la corte de Felipe IV a través de sus respectivas familias, debieron conocer también el Sumo Sacramento de la Fe de Francisco Aguado. No olvidemos que Juan Domingo de Haro era hijo de Luis Méndez de Haro y Guzmán, Valido del monarca entre 1643 y 1661, y que Inés de Zúñiga era hija de Leonor María de Guzmán, hermana del Conde Duque de Olivares, y de Manuel de Zúñiga, VI Conde de Monterrey y personalidad muy destacada en la corte de Felipe IV además de fundador y mecenas, junto con su esposa, del convento de las Agustinas de Salamanca ${ }^{33}$. Por lo tanto, el conocimiento de la obra del jesuita pudo impulsar también a los Condes a tomar el grabado de su portada como modelo para la custodia que donaron al convento salmantino, si bien la convirtieron en una exaltación de la Eucaristía y de su propio linaje erigido aquí, de forma muy sutil, en protector del Sacramento a través de la breve inscripción «MONTERREY». El origen concreto y la fecha exacta de donación son difíciles de determinar puesto que la custodia no se ajusta a los diseños madrileños ni salmantinos contemporáneos conocidos, pero tuvo que ser cerca de la corte y a partir de $1656 \mathrm{o}$, incluso, ese mismo año que fue el de su matrimonio y el de la solemne profesión religiosa de su sobrina Inés en este convento ${ }^{34}$.

En cualquier caso se codifica en la platería madrileña de los últimos años de Felipe IV y del reinado de Carlos II un modelo parecido de custodia que es el que sigue, por ejemplo, el platero del rey Rafael González Sobera activo, por lo menos, desde el año $1655^{35}$. En 1683, este artífice ejecutó el ejemplar de Santa María de Orduña que presenta un águila bicéfala bien destacada en el astil, como ya había sido ensayado tres años antes en la custodia de Cartes (Cantabria), fechada en 1680. Por todo ello consideramos que debió ser entre 1640 y 1680 cuando el modelo se introdujo en la platería de Madrid y en su repertorio de dibujos para exámenes, bien a través de la actuación personal del propio González Sobera, bien por mano de algún otro maestro del entorno cortesano.

A partir de estos momentos, el tipo de custodia se vuelve a repetir con variantes accidentales en varios ejemplares madrileños de los últimos años del siglo xvir. Por una parte, la ejecutó como pieza de examen Cristóbal de Alfaro el Mozo. -Quizás fuera este mismo platero el que la-

31 Recordemos que para Covarrubias: Tesoro de la lengua castellana, edición de Martín de Riquer, Barcelona, 1943, católico significa universal y que este calificativo fue otorgado a los reyes de Castilla a partir de Recaredo y renovado a perpetuidad por el pontífice Alexandro VI en Don Fernando de Aragón, para él y sus sucesores.

32 P. Rodriguez de Monforte: Descripción de las honras que se hicieron a la Cathólica Magestad de D. Phelipe IV..., Madrid, Francisco Nieto, 1666. Biblioteca Nacional, R.4870. El estudio de los jeroglíficos en M. A. Allo: «Mensaje simbó1ico de los jeroglíficos en las exequias de Felipe IV", en Arte funerario. Coloquio Internacional de Historia del Arte,. Vol. I. Universidad Nacional Autónoma de México, México, 1987, págs. 217-229.

33 A. Madruga: op. cit., págs. 32-48.

34 Ibídem, pág. 48.

35 F. MARTin: op. cit., pág. 401. En el 1655 González Sobera entregó diversos objetos para el Servicio de Cava del Rey. 
bró poco después las custodias de los Carmelitas de Alba de Tormes (Salamanca) y del Cabildo Catedral de Madrid, ambas con la misma estructura y decoración, enriquecida en el ejemplar catedralicio por la adición de otros desnudos infantiles y sobrepuestos en el basamento-. Por otra parte, otros artífices barrocos repitieron un modelo parecido hasta los primeros años del siglo XVIII, como la custodia de Alquézar en Barbastro (Huesca). En todos estos ejemplos persiste la idea de la monarquía católica española, heredera del Sacro Imperio, encarnada en el águila bicéfala con corona imperial, como soporte para la defensa y exaltación del Sacramento de la Eucaristía, si bien el grabado original de María Eugenia Beer se simplifica en las piezas de plata eliminando el escudo, las inscripciones y las virtudes.

Es bastante probable, por otra parte, que la difusión de esta iconografía en la platería religiosa madrileña de las últimas décadas del siglo xvil estuviese también relacionada con las intrigas políticas del reinado de Carlos II en torno a la figura del valido Fernando de Valenzuela, que culminaron en la vergonzosa violación del monasterio de El Escorial por la nobleza, con la consiguiente excomunión de los nobles y el posterior acto de desagravio al Sacramento promovido por el monarca, que tuvo como consecuencia artística la ejecución del cuadro de "La Sagrada Forma" por Sánchez Coello a partir de 1685. Esta pintura, que ha sido definida por J. Brown como «retrato de grupo, alegoría religiosa y propaganda política» ${ }^{36}$, buscaba sobre todo resaltar el antiguo tema de la dinastía de los Austrias, encarnada aquí en Carlos II, como defensora terrenal de la fe. Es decir, se trataba de nuevo de poner de manifiesto la tradicional devoción de la Casa de Austria a la Eucaristía, tal y como se refleja también en las custodias con águila bicéfala que se labran en estos momentos en el entorno de la corte madrileña.

$\mathrm{Al}$ parecer, la iconografía del águila bicéfala tuvo tanto éxito que se difundió dentro y fuera de la Península hasta el siglo xix, tanto en custodia como en relicarios, sacras, atriles, joyas, llaves, etc., aunque en muchos casos, con el transcurso del tiempo, perdió su primitivo significado simbólico y sufrió notables variaciones. Un magnífico y temprano ejemplo de esta expansión es la custodia del Arzobispado de Popayán (Colombia) (Fig. 6), labrada por los artífices colombianos Antonio Rodríguez y N. Alvarez en el año 1673 37. Dado que los jesuitas se habían establecido en la ciudad por real cédula de $1633{ }^{38}$ y que el Sumo Sacramento de la Fe fue escrito por un miembro de la orden de San Ignacio en el año 1640, pudo ser la propia orden la introductora del libro y de la iconografía en esta zona. En el caso de la custodia de Popayán, la representación iconográfica presenta algunas diferencias con los ejemplos anteriores ya que es el cuerpo del águila el que alberga el viril.

El mismo tema se repite también en el expositor del Museo Diocesano de Salamanca, obra del platero salmantino Manuel García Crespo a mediados del siglo xVIII ${ }^{39}$-inspirado quizás en la antigua custodia de los Condes de Monterrey-, y en otro tipo de objetos como en los atrilessacras mexicanos del Pilar de Zaragoza fechados en $1715^{40}$, los del Museo Franz Mayer de México ${ }^{41}$, las sacras del monasterio de Tulebras (Navarra) del tercer cuarto del siglo XVIII ${ }^{42}$ y el

36 J. Brown: La Edad de Oro de la Pintura en España, Madrid, 1990, págs. 300-302.

37 Esta custodia la reproduce S. Sebastián: El Barroco Iberoamericano. Mensaje iconográfico, Madrid, 1990, Fig. 49. La comenta M. E. Valencia de Redondo: «Núm. 250» del catálogo de La Iglesia en América. Evangelización y Cultura. Pabellón de la Santa Sede, Exposición Universal, Sevilla, 1992.

38 S. Sebastián López; J. de Mesa Figueroa; T. Gisbert de Mesa: Arte Iberoamericano desde la colonización a la independencia, Madrid, 1986, Vol. II, pág. 321.

39 M. Pérez Hernández: op. cit., núm. 280 y foto portada.

40 J. F. Esteban Lorente: “Unas piezas de platería barroca mexicana en Zaragoza», Cuadernos de Investigación, 2 (1975), pág. 105. Fig. 2.

41 C. Esteras Martín: "Platería virreinal novohispana», núm. 60, en El arte de la platería mexicana. 500 años, México, 1989-90.

42 M. C. Garcta Gainza; M. C. Heredia Moreno; J. Rivas Carmona y M. Orbe Sivatte: op. cit., pág. 401, lám. 673. 
marco mexicano de la catedral de Burgos ${ }^{43}$. También encontramos la iconografía del águila bicéfala en el dosel de San Miguel de Jerez de la Frontera, de hacia $1700^{44}$, en las llaves de la ciudad de Lima ejecutadas por el platero limeño Agustín Liñán en torno a 1800 45, en los medallones del Santo Rostro del Museo Arqueológico Nacional, probables obras giennenses de la primera mitad del siglo XIX ${ }^{46}$, y en algunas otras joyas inéditas y anónimas.

El hecho de que los atriles-sacras del Pilar de Zaragoza conserven marcas de Mexico, ha dado lugar a que con frecuencia se hayan considerado mexicanas todas las piezas que ostentan esta misma iconografía. Sin embargo, hay que tener en cuenta que varias de las obras más significativas se documentan en Madrid o se relacionan con la Corte, como las custodias de Orduña, Valtierra y Agustinas de Salamanca, y que el grabado de María Antonia Beer es la portada de un libro editado en Madrid en el año 1640. De todo ello se deduce que el origen del águila bicéfala en la platería religiosa se encuentra precisamente en el grabado del «Sumo Sacramento de la Fe» de Francisco Aguado y en el entorno de la corte española de Felipe IV. Desde aquí el tema pudo introducirse en la platería como elemento fundamental de las custodias de sol a través de una triple vertiente. En primer lugar, mediante el mecenazgo de los VII Condes de Monterrey en el convento de las Agustinas de Salamanca (custodia donada al convento). También, gracias a la actuación personal de algunos plateros relacionados con la corte de los Austrias que la incorporarían en sus trabajos (caso de Rafael González Sobera en la custodia de Orduña) y en los repertorios de los dibujos para exámenes (así lo demuestra la custodia de Valtierra labrada por Cristóbal de Alfaro con ocasión de su examen de maestro). Por último, por medio de la propia Orden Jesuita, uno de cuyos miembros había sido el autor del "Sumo Sacramento de la Fe" e inspirador de la portada con el grabado eucarístico, el tema del águila bicéfala pudo pasar a la platería colombiana (caso de la custodia de Popayán) y difundirse por Hispanoamérica.

Con posterioridad, a lo largo del siglo XVIII y primera mitad del XIX, la iconografía del águila bicéfala se incorporó a otras obras de plata de tipología distinta y ya descontextualizadas de su primitivo significado simbólico de exaltación eucarística por parte de la monarquía española.

43 L. S. Iglesias Rouco: Platería Hispanoamericana en Burgos, Burgos, 1991, pág. 57.

44 P. Nieva Soto: Plata y plateros en la iglesia de San Miguel de Jerez, Jerez, 1988, págs. 104-105, Fig. 23.

45 M. C. Heredia Moreno: "Notas sobre plateros limeños de los siglos xvi, XviII y XIX», Cuadernos de Arte Colonial, 8 , mayo 1992, pág. 44.

46 J. M. Cruz Valdovinos: Museo Arqueológico Nacional. Catálogo de la Platería, Madrid, 1982, núms. 81-82. 